\title{
Scherbius wind farm based fuzzy SSSC
}

\author{
Talebi Abderrahmane, Tedjini Hamza
}

SGRE Laboratory Tahri Mohamed University, Algeria

\begin{tabular}{l}
\hline Article Info \\
\hline Article history: \\
Received Aug 24, 2019 \\
Revised Feb 14, 2020 \\
Accepted Mar 20, 2020 \\
\hline
\end{tabular}

Keywords:

FACTS

IEEE 14 bus grid

SSSC

Voltage drop

\begin{abstract}
The wind is a clean, free, and readily available renewable energy source, it is cost-effective in several regions, it is a domestic source of energy and it is a sustainable source of energy. The SSSC system is a FACTS voltage compensator, it is inserted in series with the electrical transmission line through a coupling transformer, its role is to inject a voltage which allows to influence the active power transmitted. The goal of this paper is to examine the effect of using a wind farm SSSC to improve flexibility of a multimachine perturbed network.
\end{abstract}

This is an open access article under the CC BY-SA license.

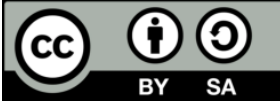

Corresponding Author:

Tédjini Hamza,

SGRE Laboratory,

Tahri Mohamed University,

Bechar, 08000Algeria.

Email: tedjini_h@yahoo.fr

\section{INTRODUCTION}

The world energy market wind turbine is growing faster than any other renewable energy source. Total worldwide, which did not exceed $4800 \mathrm{MW}$ in 1995, reached $318000 \mathrm{MW}$ in 2013, after $158505 \mathrm{MW}$ in 2009, 74,052 MW in 2006 and 93,835 MW in 2007 and 120,297 MW in 2008, according to forecasts 2011 GWEC, global capacity is expected to reach 493,330 MW by the end of 2016. By 2020, their approximately $832,000 \mathrm{MW}$ of installed capacity [1,2].

The synchronous series static compensator SSSC is a modern FACTS which provides voltage compensation, it is placed directly on the line [3]. Its presence translates into several advantages in terms of loss and planning and energy circulation $[4,5]$.

The phenomena that impair the quality of electrical energy are of different natures: short circuit, voltage dips, breakdowns, harmonic pollution. Whatever the origin of these disturbances, it is essential to maintain or improve the quality of the electricity that passes through the transmission and distribution networks $[6,7]$.

In this work we will study the advantage of the uses of wind-SSSC to increase transit power stability in the case of multi bus, multi machines perturbed network.

\section{SCHERBIUS DFIG WIND SYSTEM}

The Scherbius wind turbine system using a DFIM and an indirect matrix converter back-to-back converter, has many assets [8-10]. One of the advantages of this configuration is that the power elements 
used are dimensioned to pass part of the total power of the system, which makes it possible to reduce the power losses, illustrated in Figure $1[11,12]$.

The dual feed induction machine is a powered rotor asynchronous machine with stator windings connected to the network through a power converter [13, 14]. The simplified model is presented in Figure 2 [15].

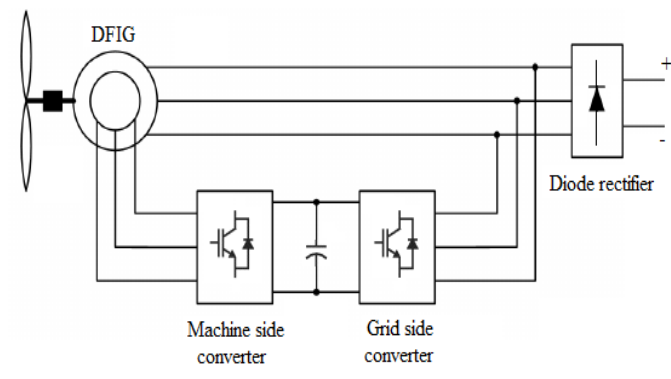

Figure 1.Wind system compenents

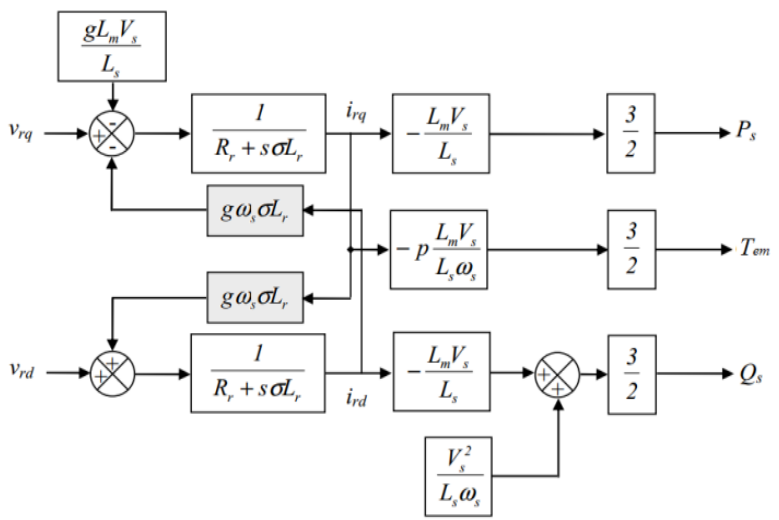

Figure 2.Simplified model of DFIG

The wind farm is an association of several wind turbines in series, each one is constitued of a double feed asynchronous machine, $850 \mathrm{~kW} / 690 \mathrm{~V}$ wound rotor sized for an air density of $1.225 \mathrm{~kg} / \mathrm{m}^{3}$ with a rotation speed between 14.6 and $30.8 \mathrm{rpm}$ [16-18].

\section{STATICS SYNCHRONOUS SERIES COMPENSATOR BASED WIND FARM}

The composition of the synchronous static compensator in series of (SSSC) is based on three parts: the first is a continuous source or else the continuous storage element which is behaved from batteries, it will be determined according to the need for network, the second part is presented by the DC-AC converter and with the help of the command it can be used as an adjustable voltage source, the third part presents the output filter es the series coupling transformer, as described in Figure 3 [19, 20].

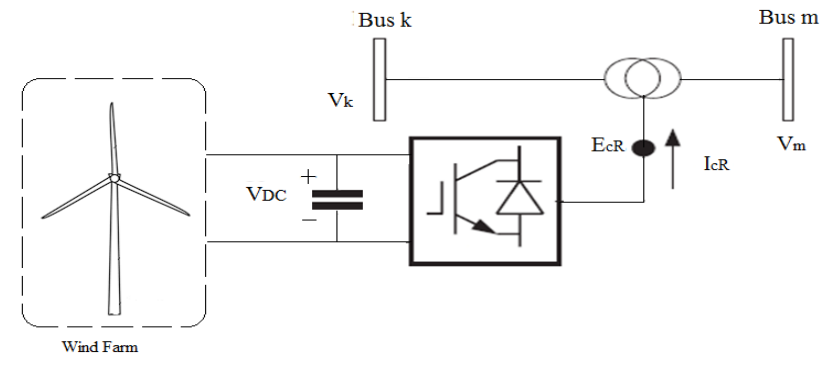

Figure 3. Configuration of wind WSSSC

\subsection{Modelling and control of WSSSC}

Figure 4 shows the equivalent circuit of the network equipped with the synchronous series static compensator [21]. 


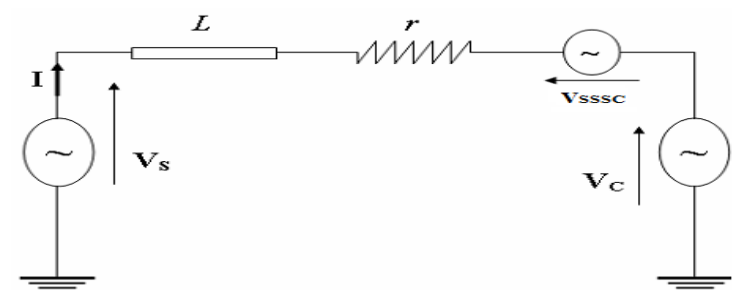

Figure 4.WSSSC model in the case of insertion between two generator bus

The $\mathrm{r}$ and $\mathrm{L}$ are parameters of including series transformer. The dynamic behavior of currents in Park coordinate system is given by:

$$
\frac{d}{d t}\left[\begin{array}{l}
i_{d} \\
i_{q}
\end{array}\right]=\left[\begin{array}{cc}
-\frac{r}{L} & \omega \\
-\omega & -\frac{r}{L}
\end{array}\right] \cdot\left[\begin{array}{l}
i_{d} \\
i_{q}
\end{array}\right]+\frac{1}{L}\left(\left[\begin{array}{l}
V_{d} \\
V_{q}
\end{array}\right]-\left[\begin{array}{c}
V_{c d} \\
V_{c q}
\end{array}\right]-\left[\begin{array}{c}
V_{d}^{\prime} \\
V_{q}^{\prime}
\end{array}\right]\right)
$$

The active $\mathrm{P}$ and reactive powers $\mathrm{Q}$ to be controlled are given by equations (2) and (3) below:

$$
\begin{aligned}
& P=\frac{3}{2}\left(V_{d} \cdot i_{d}+V_{q} \cdot i_{q}\right) \\
& Q=\frac{3}{2}\left(V_{q} \cdot i_{d}-V_{d} \cdot i_{q}\right)
\end{aligned}
$$

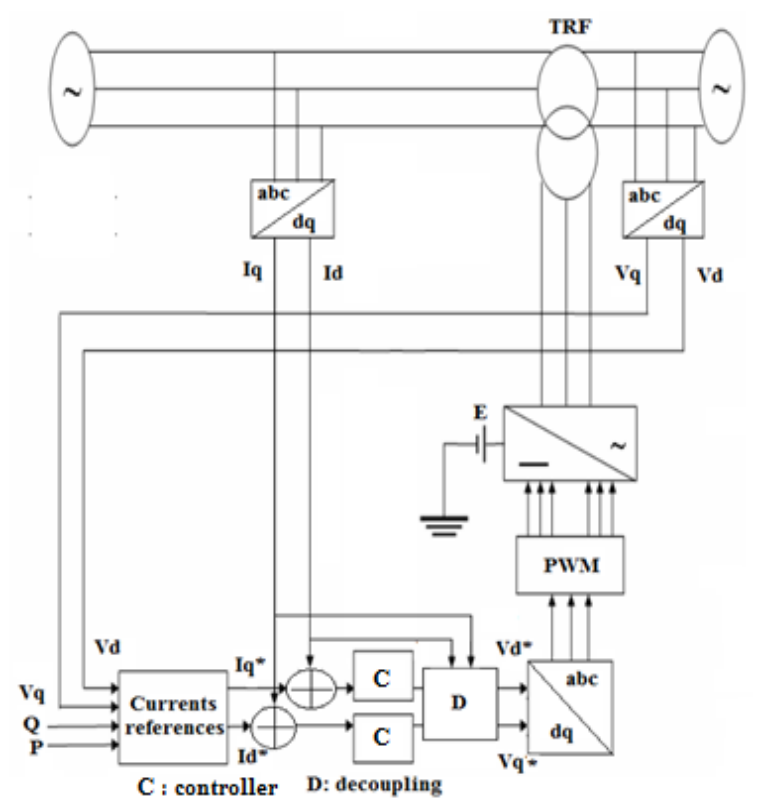

Figure 4. Control circuit of SSSC

\subsection{Fuzzy control}

Some processes are inherently difficult to model because they vary over time or cannot be correctly represented by a linear model. In this case, the regulator setting parameters will not be optimal and the 
system may not be properly controlled. This is why we introduce the notion of fuzzy logic [22]. Figure 5 shows the decomposition into three main stages of a fuzzy controller [23].

a. Fuzzification of the inputs is the evaluation of the membership functions of the input variables.

b. The inference engine: the evaluation of the output functions by the rules table

c. Dfuzzification: evaluation of the fuzzy controller output by calculating the center of gravity) [24].

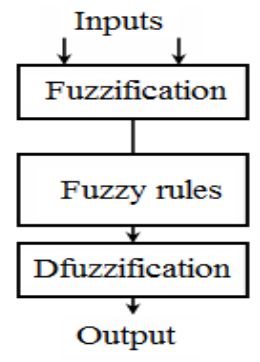

Figure 5. Fuzzy controller Steps

\section{STUDIED SYSTEM}

Our objective is to examine the effect of the synchronic static serial compensator on the stability of an IEEE-14 node network, and demonstrate its feasibility. In a first section, the IEEE-14 bus network will be presented, and after that in a second section, a fault near a generator node will be applied under the simulation study; and finally, the WSSSC will be introduced to solve the problem of voltage drop propagation $[25,26]$. The WSSSC is installed in the most perturbed in the node 8 as shown in Figure 6.

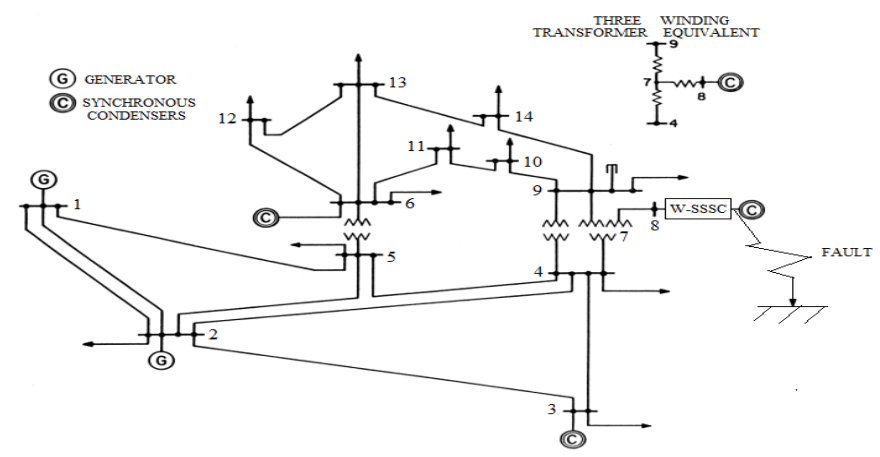

Figure 6. Perturbed IEEE 14 bus network

\subsection{Without compensation}

The Figures from 7 to 20 show the voltage curve in eache node of network, in this case the WSSSC is not installed and we can examine the fault propagation consequences in all of nodes between times $0,5 \mathrm{~s}$ and $0,7 \mathrm{~s}$.

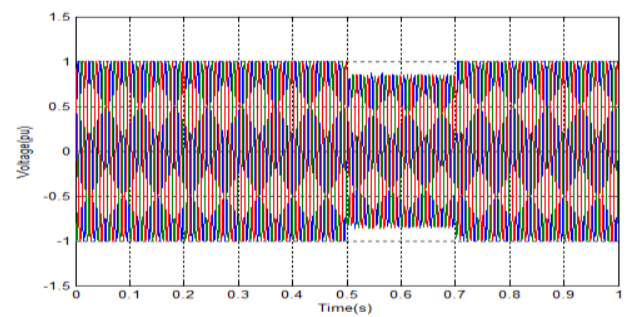

Figure 7. Bus 1 Voltage

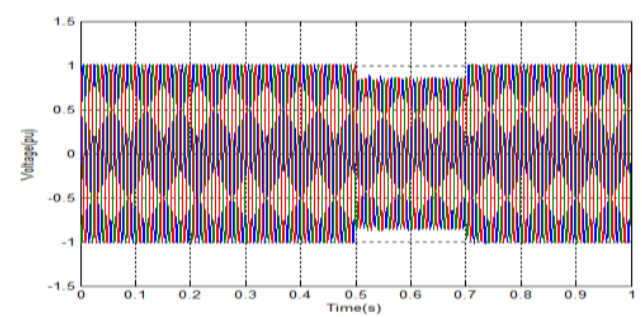

Figure 8. Voltage at node 2 


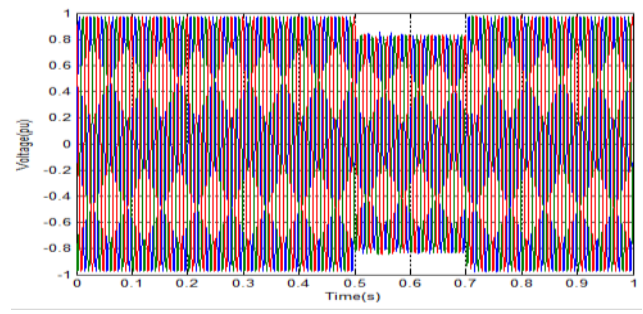

Figure 9.Tension at bus 3

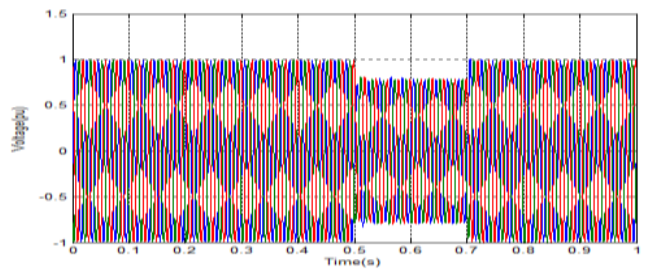

Figure 11.Node 5 voltage

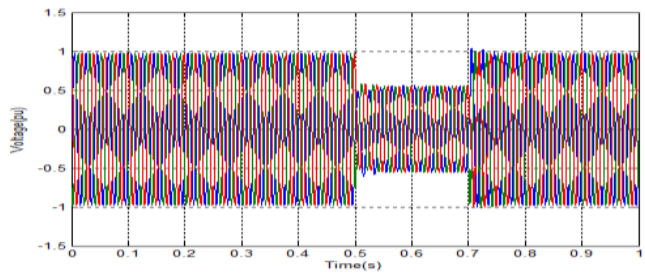

Figure 13. Voltage at bus 7

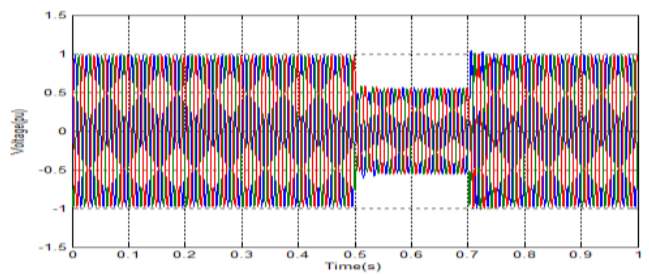

Figure 15.Tension at bus 9

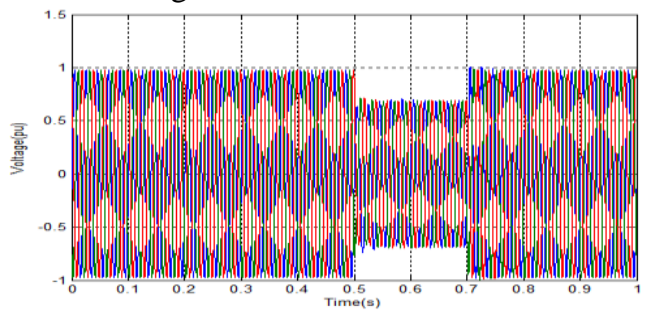

Figure 17.Bus 11 voltage

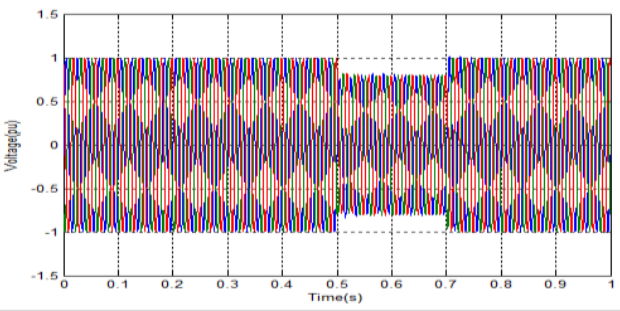

Figure 10.bus 4 voltage

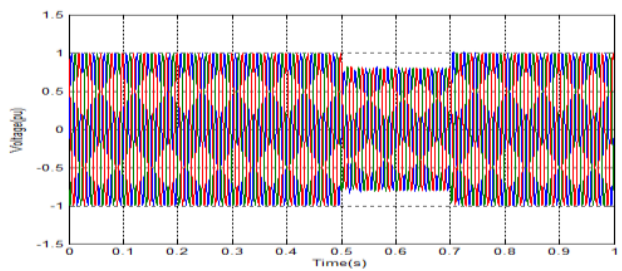

Figure 12.Node 6 tension

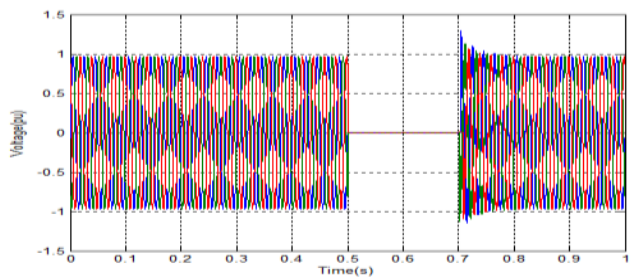

Figure 14.Node 8 voltage

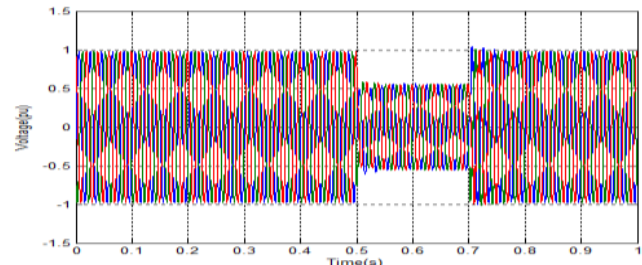

Figure 16.Tension at node 10

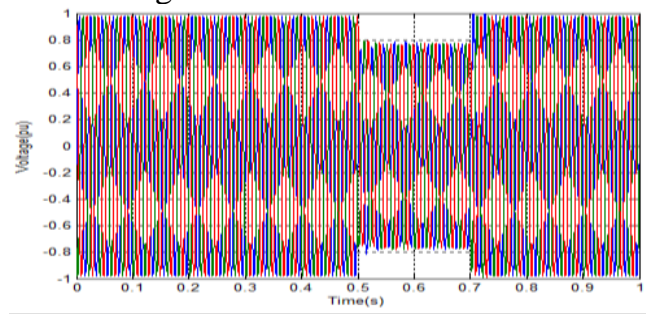

Figure 18.Bus 12 voltage 


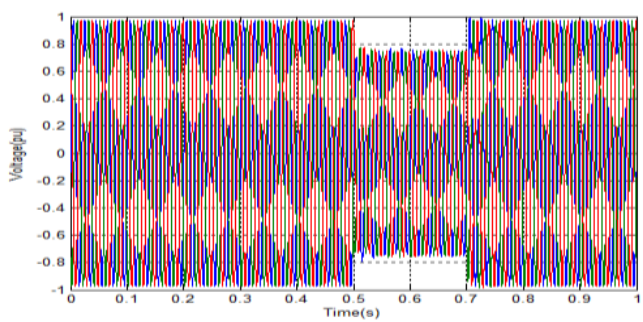

Figure 19.Bus 13 tension

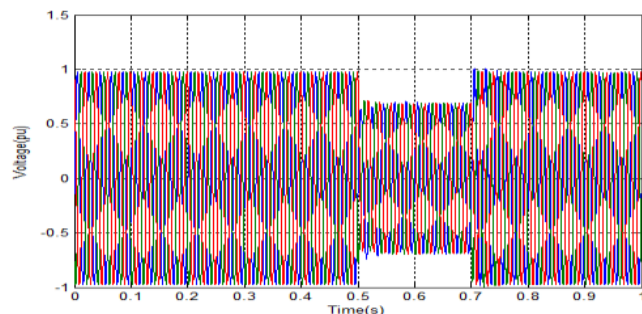

Figure 20.Bus 14 tension

\subsection{Uses of WSSSC}

In this case the WSSSC is connected to the bus 8, As in the previous section, we present the voltage curve in eache node of network in Figures 21 to 34, the voltage of WSSSC is mentioned in Figure.35, the impact of this voltage restore the network to its stability and cancela te the propagation of the disturbance caused by the fault.

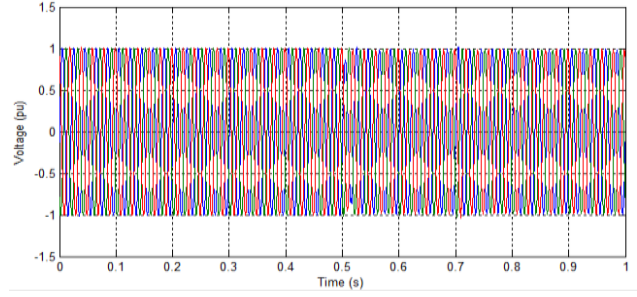

Figure 21. Voltage at node 1

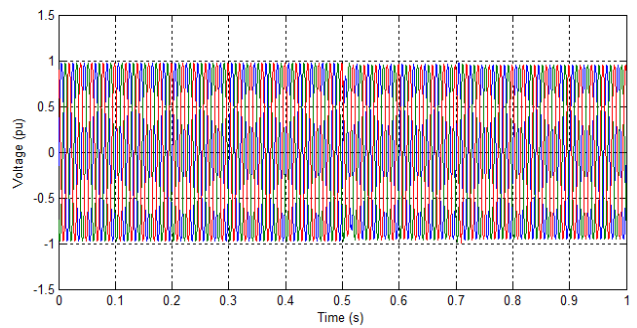

Figure 23.Node 3 voltage

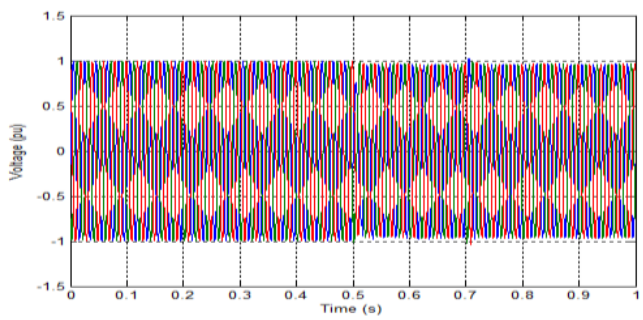

Figure 25.Tension of node 5

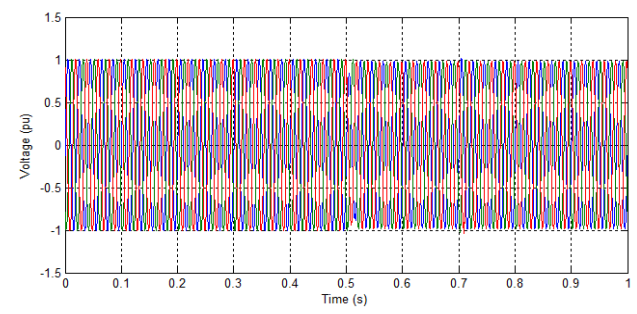

Figure 22. Voltage at node 2

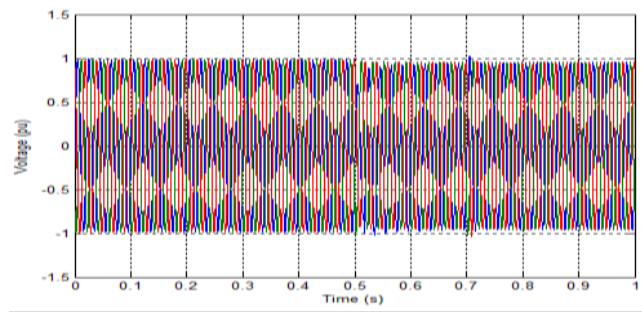

Figure 24.Node 4 voltage

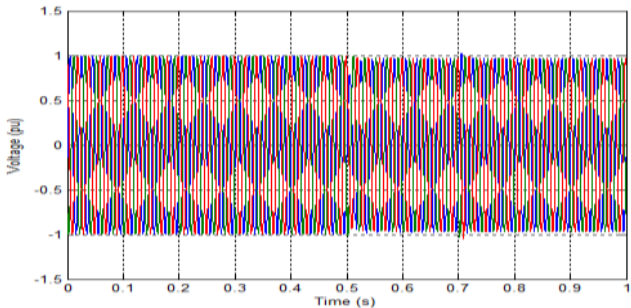

Figure 26.Tension of node 6 


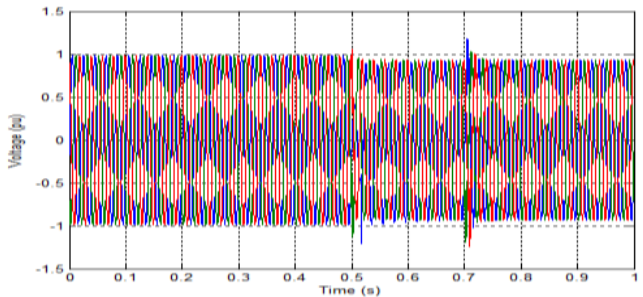

Figure 27.Tension of bus 7

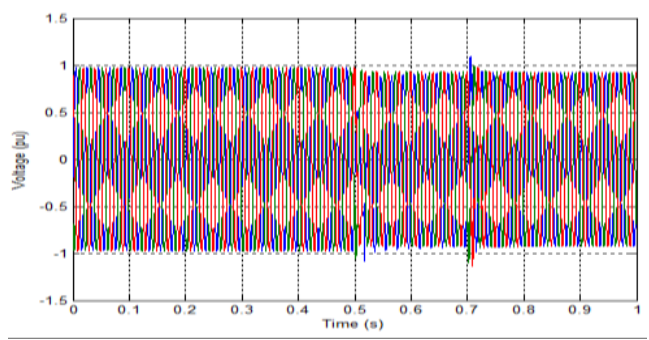

Figure 29.Bus 9 voltage

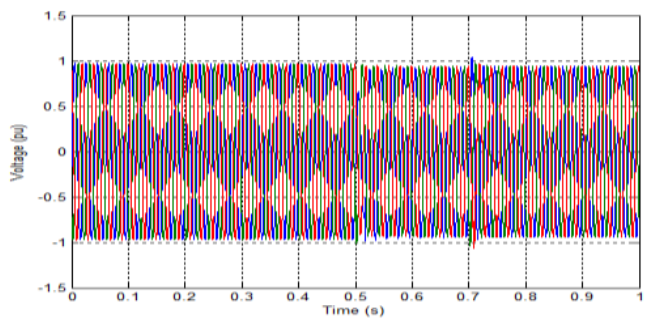

Figure 31.Node 11 tension

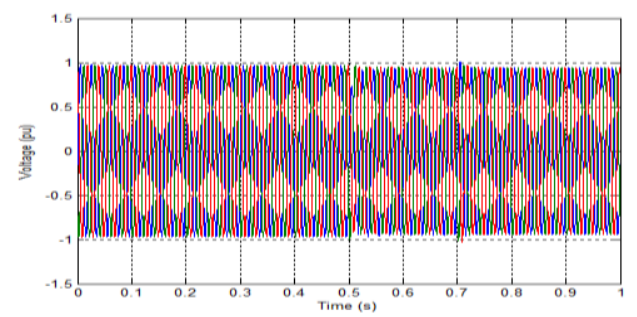

Figure 33.Node 13 voltage

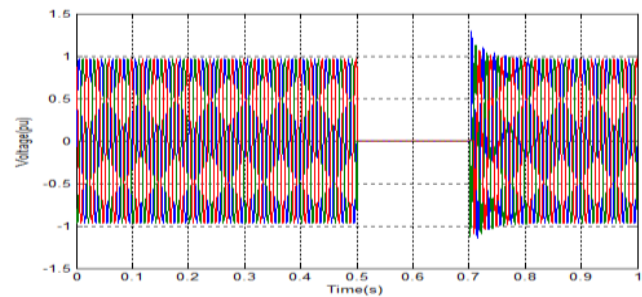

Figure 28.Tension of bus 8

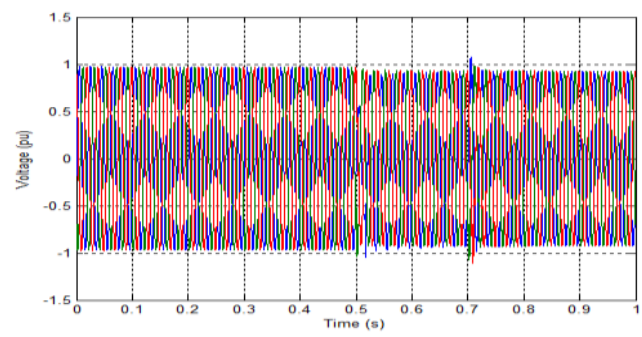

Figure 30.Bus 10 voltage

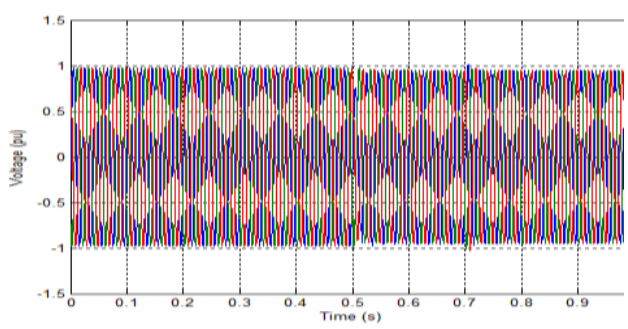

Figure 32.Node 12 tension

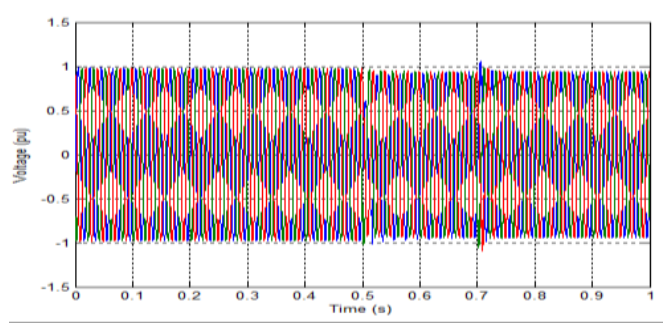

Figure 34 .Node 14 voltage

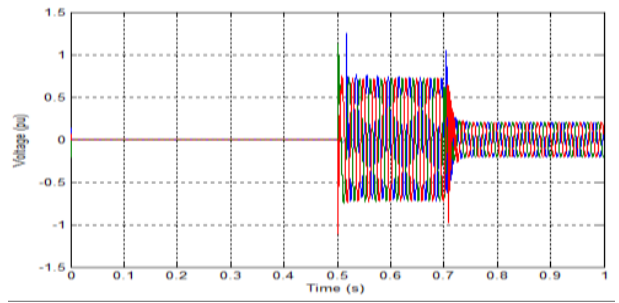

Figure 35. Voltage gouverned of WSSSC 


\subsection{Discussion of results}

Table 1 shows the voltage drop in the nodes. There is a deletion almost total voltage drop for all nodes except bus 8 (the default location).

The WSSSC prevents the consequences of the fault (voltage drop, harmonics,...) from reaching the other regions of the electrical network.

The SSSC can't manage to eliminate the consequences of the defect totally, and this amounts to the maximum compensation capacity delivered by the WSSSC.

Table 1. The tainsient voltage drop

\begin{tabular}{ccc}
\hline Bus & Withoutcompensation & With WSSSC \\
\hline 1,2 & $18 \%$ & $1.3 \%$ \\
3 & $21 \%$ & $2.8 \%$ \\
$4,5,6$ & $26 \%$ & $4.5 \%$ \\
$7,9,10$ & $47 \%$ & $8 \%$ \\
11,14 & $34 \%$ & $8 \%$ \\
12 & $22 \%$ & $7 \%$ \\
13 & $25 \%$ & $6 \%$ \\
\hline
\end{tabular}

\section{CONCLUSION}

In this work, we examine the impact of a cascading wind farm as an SSSC which is a FACTS capable of compensating for voltage, faced with the propagation of voltage drops in the case of the IEEE 14 bus. The results obtained show that WSSSC provide a strong action in the voltage compensation and reduction of losses in power lines. Its uses make it possible to cancel the propagation of voltage drops in the network. However, in the case of a multi-machine network and loop lines, several compensators must be used to obtain perfect compensation.

\section{ACKNOWLEDGEMENTS}

This work is supported by SGRE Laboratory.

\section{REFERENCES}

[1] V. Yaramasu, B. Wu, P. C. Sen, S. Kouro and M. Narimani, "High-power wind energy conversion systems: Stateof-the-art and emerging technologies,"IEEE trans., pp. 740-788,2015.

[2] M. B. H. Kumar and B. Saravanan, "Impact of global warming and other climatic condition for generation of wind energy and assessing the wind potential for future trends,"IEEE Innovations in Power and Advanced Computing Technologies (i-PACT), 2017.

[3] K. Brian Johnso, "How FACTS Controllers Function in an AC Transmission System Series and Combined Multiterminal Controllers,"IEEE trans., pp. 960, Aug 012010.

[4] H. Zenk and A. S. Akpinar, "PI, PID and fuzzy logic controlled SSSC connected to a power transmission line, voltage control performance comparison,"4th International Conference on Power Engineering, Energy and Electrical Drives, 2013.

[5] G. Maheswaran and K. Siddappa Naidu, "Comparison of fuzzy and PI controller based SSSC for damping of sub synchronous resonance,"International Conference on Science Engineering and Management Research (ICSEMR), 2014.

[6] C. E. Prasad and S. Vadhera, "Fuzzy logic based SSSC as sub-synchronous resonance damping controller,"International Conference on Energy, Power and Environment: Towards Sustainable Growth (ICEPE), 2015.

[7] J. Nayak, Bharothu, and K. Lalitha, "Compensation of voltage flicker by using facts devices,"American Journal of Electrical Power and Energy Systems, vol. 2, no. 3, pp. 66-80,2013.

[8] K.Rabyi and H. Mahmoudi, "Energy storage of DFIG based wind farm using D-STATCOM", Vol 9, No 2: April 2019,"International Journal of Electrical and Computer Engineering (IJECE), vol. 8, no. 2, Apr 2018.

[9] D. C. Phan and T. H. Trinh, "Maximum Power Extraction Method for a Doubly-fed Induction Generator Wind Turbine,"International Journal of Electrical and Computer Engineering (IJECE), vol. 8, no. 2, Apr 2018.

[10] M. Bouderbala, B. Bossoufi, A. Lagrioui, M. Taoussi, H. A. Aroussi, and Y. Ihedrane, "Direct and indirect vector control of a doubly fed induction generator based in a wind energy conversion system,"International Journal of Electrical and Computer Engineering (IJECE), vol. 9, no 3, Jun 2019.

[11] H. Vallecha, Shivam, "Smart utilization of solar and wind power farm inverters as SSSC in grid connected renewable energy system,"IEEE 6th International Conference on Power Systems (ICPS), 4-6 March, 2016.

[12] M. Al-Sarray and R. A. McCann, "Control of an SSSC for oscillation damping of power systems with wind turbine generators,"IEEE Power \& Energy Society Innovative Smart Grid Technologies Conference (ISGT), 23-26 April, 2017. 
[13] G.P. Prajapat, N. Senroy, and I. N. Kar, "Modified Control of DFIG-WT for the Smooth Generator Speed Response under Turbulent Wind," 14th IEEE India Council International Conference (INDICON), 2017.

[14] S. Mensou, A. Essadki, I. Minka, T. Nasser, B. B. Idrissi, and L. Ben Tarl, "Performance of a vector control for DFIG driven by wind turbine: real time simulation using DS1104 controller board," vol. 10, no. 2, Jun 2019.

[15] M. Nadour, A. Essadki, T. Nasser, and M. Fdaili, "Robust coordinated control using backstepping of flywheel energy storage system and DFIG for power smoothing in wind power plants," vol. 10, no. 2, Jun 2019.

[16] D. N. Truong, Q. C. Tran, P. N. Tran, and M. S. Nguyen Thi, "ANFIS Damping Controller Design for SSSC to Improve Dynamic Stability of a Grid Connected Wind Power Systems," International Conference on System Science and Engineering (ICSSE) 28-30 June, 2018

[17] V. U. Muthu, M. A. Bhaskar, A. Arthur, T. Kumar, and S.K. Surya, "Modeling of wind energy based SSSC for voltage stability enhancement,"International Conference on Electronics and Communication Systems (ICECS), 2014.

[18] D. C. Phan and T. H. Trinh, "Maximum Power Extraction Method for a Doubly-fed Induction Generator Wind Turbine,"International Journal of Electrical and Computer Engineering (IJECE), vol. 8, no. 2, Apr 2018.

[19] D. Murali1 and M. Rajaram, "Use of ANFIS Control Approach for SSSC based Damping Controllers Applied in a Two-area Power System,"Journal of Applied Research and Technology, vol. 11, no. 6, pp. 803-931, Dec 2013.

[20] G. Beck, W. Breuer, D. Povh, D. Rtzmann, "Use of Facts for system Performence Improvement", CEPSI conference, India.6-10 Nov. 2006, pp. 7.

[21] M. Rohal, Ravi, "Analysis of Power System Oscillation Damping \& Voltage Stability Improvement Using SSSC in A Multimachine System,"International Journal of Engineering Research andTechnology, vol. 3, no. 7, 2014.

[22] A. H. Lone, V. Yousuf, S. Prakash, and M. A. Bazaz, "Load Frequency Control of Two Area Interconnected Power System using SSSC with PID, Fuzzy and Neural Network Based Controllers,"2nd IEEE International Conference on Power Electronics, Intelligent Control and Energy, 2018.

[23] C. E. Prasad and S. Vadhera, "Fuzzy logic based SSSC as sub-synchronous resonance damping controller,"International Conference on Energy, Power and Environment: Towards Sustainable Growth (ICEPE), 2015.

[24] M. Benmeziane, S. Zebirate, A. Chaker and Z. Boudjema, "Fuzzy sliding mode control of doubly-fed induction generator driven by wind turbine,"IJPEDS, vol.10, no. 3, pp. 1592-1602, 2019.

[25] N. A. Daw and A. H. Salih, "Choosing the Best Place of Static Var Compensator in IEEE 14 Bus System to Improve Voltage using Neplan Software,"IEEE 19th International Conference on Sciences and Techniques of Automatic Control and Computer Engineering (STA), 2019.

[26] G. Bagha and A. Kumar, "Voltage Profile Enhancement for IEEE-14 Bus System using UPFC, TCSC and SSSC,"2nd IEEE International Conference on Power Electronics, Intelligent Control and Energy Systems (ICPEICES), 2018.

\section{BIOGRAPHIES OF AUTHORS}

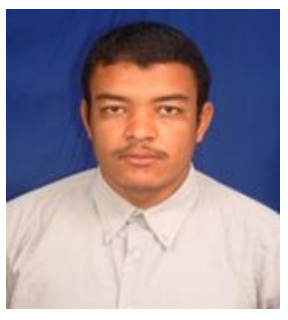

Talebiabderrahmane: member of SGRE laboratory. Received the M.Sc. degree from the university of Djilaliliabes -Sid belabbes- Algeria in 2010, Actually he is a head of the wind power unit SonelgazAdrar, Algeria.

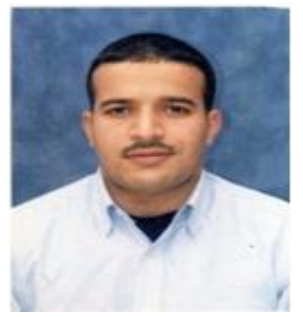

Tedjini hamza: member of SGRE laboratory. Received the M.Sc. degree from the university of IbnKhaldoun -Tiaret- Algeria in 2007, and the Ph.D. degree the University of Sciences and Technology Mohammed Boudhiaf of Oran (USTO-MB) in 2012. Actually he is a professor of electrical engeneering in Mohammed Tahri university, Bechar, Algeria. 